\title{
A scale-dependent blending scheme for WRFDA: impact on regional weather forecasting
}

\author{
H. Wang ${ }^{1,2,3}$, X.-Y. Huang ${ }^{1}$, D. Xü ${ }^{4}$, and J. Liu ${ }^{4}$ \\ ${ }^{1}$ National Center for Atmospheric Research, Boulder, CO, USA \\ ${ }^{2}$ Earth System Research Laboratory, NOAA, Boulder, CO, USA \\ ${ }^{3}$ Colorado State University, Fort Collins, CO, USA \\ ${ }^{4}$ Nanjing University of Information Science \& Technology, Nanjing, China \\ Correspondence to: H. Wang (hongli.wang@noaa.gov)
}

Received: 10 March 2014 - Published in Geosci. Model Dev. Discuss.: 15 April 2014

Revised: 18 July 2014 - Accepted: 21 July 2014 - Published: 28 August 2014

\begin{abstract}
Due to limitation of the domain size and limited observations used in regional data assimilation and forecasting systems, regional forecasts suffer a general deficiency in effectively representing large-scale features such as those in global analyses and forecasts. In this paper, a scaledependent blending scheme using a low-pass Raymond tangent implicit filter was implemented in the Data Assimilation system of the Weather Research and Forecasting model (WRFDA) to reintroduce large-scale weather features from global model analysis into the WRFDA analysis. The impact of the blending method on regional forecasts was assessed by conducting full cycle data assimilation and forecasting experiments for a 2-week-long period in September 2012.

It is found that there are obvious large-scale forecast errors in the regional WRFDA system running in full cycle mode without the blending scheme. The scale-dependent blending scheme can efficiently reintroduce the large-scale information from National Centers for Environmental Prediction (NCEP) Global Forecast System (GFS) analyses, and keep small-scale information from WRF analyses. The blending scheme is shown to reduce analysis and forecasting error of wind, temperature and humidity up to $24 \mathrm{~h}$ compared to the full cycle experiments without blending. It is also shown to increase precipitation prediction skills in the first $6 \mathrm{~h}$ forecasts.
\end{abstract}

\section{Introduction}

Data assimilation that provides the optimal estimation of true atmospheric state is a multiscale problem, since the atmosphere consists of multiscale systems. It is important that the data assimilation system for a limited area model (LAM) can capture the multiscale features of atmospheric systems, including the systems whose length scales are longer than the LAM domain. However, previous studies found that the LAM analyses and forecasts suffer a general deficiency in effective representation of large-scale features (e.g., Yang, 2005a, b; Guidard and Fischer, 2008) due to limited domain size and missing observations outside the LAM domain. In addition, lateral boundary condition formulation errors can have an adverse effect on the large-scale three-dimensional shape and propagation properties of large-scale baroclinic waves in the atmosphere (Guidard and Fischer, 2008).

A partial cycle strategy can be employed in regional data assimilation and forecast systems to reintroduce large-scale weather information by restarting the data assimilation cycle in which the background is initiated from a global analysis (Hisao et al., 2012; Sun et al., 2012; Wang et al., 2013a). A similar method, which relies on a restart of the forecast when a forecast error is detected by the boundary error procedure, was proposed by Termonia et al. (2009). However, the above two methods lost small-scale features that had been built up in previous forecast cycles, and they need a few hours for model spin-up. 
In recent years, efforts have been made to correct the large-scale analysis errors in regional data assimilation systems. One possible solution is to "blend" large-scale information produced by a host model (e.g., global model) into LAM. Blending can be directly implemented by an interpolation method in spectral space or grid-point space (Guidard and Fischer, 2008). In addition to the interpolation method, Brozkova et al. (2001) proposed a digital filter blending method that filters both the LAM forecast fields and the global analysis, on a low-resolution grid, and then adds the difference between them to the LAM forecast. Yang (2005a) proposed using a spatial filter to incrementally blend ECMWF (European Centre for Medium-Range Weather Forecasts) and HIRLAM (High Resolution LimitedArea Model) analyses. This technique is referred as "analysis blending". Yang (2005b) also proposed a "background blending" scheme to blend the ECMWF forecast and the HIRLAM forecast to provide background for the HIRLAM analysis. This scheme can efficiently reintroduce information from the host model (Yang, 2005a, b) and has increased operational HIRLAM forecasting accuracy (Eerola, 2013). Tudor and Termonia (2010) proposed a spectral nudging method for nesting a LAM in a larger-scale model. They made a feasibility study of such a method that improved the lateral boundary condition (LBC) temporal resolution problem within the buffer zone at the lateral boundary of the domain.

Guidard and Fischer (2008) proposed a statistical approach that first considers the global-analysis data as an extra source of information to be added to the cost function of a variational data assimilation system. They assimilated information from the global Action de Recherche Petite Echelle et Grand Echelle (ARPEGE) model analysis into the regional Aire Limitée Adaption Dynamique Développement Inter-National (ALADIN) model by adding the ARPEGE analysis as a constraint in the data assimilation. More recently, Dahlgren and Gustafsson (2012) took a slightly different approach by assimilating only vorticity information from ECMWF forecasts into the data-assimilation system of the regional HIRLAM model. Liu and Xie (2012) showed that assimilating large-scale flows from global forecasts into a regional model improved track and intensity forecasting of Hurricane Felix (2007).

In this paper, we adopted the blending method (Yang, 2005a, b) to blend short-range analysis (forecast) fields from a coarse-resolution (global) host model to improve the quality of the analysis (background) in the WRFDA system. The blending is achieved through using a low-pass Raymond sixth-order tangent implicit filter (Raymond, 1988; Raymond and Garder, 1991). The primary goal of such a blending is to improve the description of large-scale features in the WRFDA analysis, thus to increase the WRF model regional weather prediction skill. Both the background blending and analysis blending schemes are tested. In the background blending scheme, a short forecast from the National Centers for Environmental Prediction (NCEP) Global Forecast
System (GFS), instead of an analysis, is used to reduce the possibility of error correlations between the host model field and the observations used in the regional model data assimilation. Compared to the partial cycle strategy, it always keeps small-scale information from the previous cycle, and thus it is expected to reduce spin-up issue.

The structure of the paper is as follows. Section 2 introduces the blending method. In Sect. 3, the WRF model, WRFDA system, and experiment design are described. The experimental results are presented in Sect. 4. A summary and discussion are given in Sect. 5.

\section{Methodology}

\subsection{The blending scheme}

The component of a field $x$ at length scale $l$ can be split into a filtered part and a residual part with a low-pass filter,

$x(l)=\alpha(l) x(l)+\phi(l)$,

where $\alpha(l)$ is a scale-dependent response function of the filter, $\alpha(l) x(l)$ is the filtered field of $x(l)$, and $\phi(l)$ is the residual field.

Following the above idea for a field from a host model, $x^{\mathrm{h}}$ and, for a field from a nested regional model, $x^{\mathrm{r}}$ (whose components are at scale $l$ ) can be written as

$$
\begin{aligned}
& x^{\mathrm{h}}(l)=\alpha(l) x^{\mathrm{h}}(l)+\phi^{\mathrm{h}}(l), \\
& x^{\mathrm{r}}(r)=\alpha(l) x^{\mathrm{r}}+\phi^{\mathrm{r}}(l) .
\end{aligned}
$$

Blending information from a host model $x^{\mathrm{h}}$ and a regional model $x^{\mathrm{r}}$ at scale $l$ can be expressed as (Yang, 2005a)

$x^{\text {bld }}(l)=x^{\mathrm{r}}(l)+\left[\alpha(l) x^{\mathrm{h}}(l)-\alpha(l) x^{\mathrm{r}}(l)\right]$.

It is seen that the large-scale adjustment to the regional forecast is introduced by $\alpha(l) x^{\mathrm{h}}(l)-\alpha(l) x^{\mathrm{r}}(l)$.

Equation (4) can be rewritten as

$x^{\text {bld }}(l)=\alpha(l) x^{\mathrm{h}}(l)+[1-\alpha(l)] x^{\mathrm{r}}(l)$.

The final blending field is

$x^{\mathrm{bld}}=\sum_{l} x^{\mathrm{bld}}(l)$,
$=\sum_{l} \alpha(l) x^{\mathrm{h}}(l)+\sum_{l}\left\{[1-\alpha(l)] x^{\mathrm{r}}(l)\right\}$.

Using Eq. (3), Eq. (6b) can be rewritten as

$=\sum_{l} \alpha(l) x^{\mathrm{h}}(l)+\sum_{l} \phi^{\mathrm{r}}(l)$.

For a low-pass filter, the first item in Eqs. (6b) and (6c), i.e., $\alpha(l) x^{\mathrm{h}}(l)$, represents the relatively large-scale information in a host model, where the second term on the right 
hand of Eqs. (6b) and (6c) is the relative small-scale information in a regional model. It is obvious that the blending method achieves the goal on use of large-scale information from a host model, whereas small-scale information from a regional model. $x^{\mathrm{h}}$ can be a forecast or analysis from a host model, and $x^{\mathrm{r}}$ can be a forecast or analysis from a nested regional forecast. The term background (analysis) blending means that both $x^{\mathrm{h}}$ and $x^{\mathrm{r}}$ are forecasts (analyses).

\subsection{Implementation in WRFDA}

The WRFDA system is designed to provide initial conditions for the WRF model. WRFDA is developed and maintained at the National Center for Atmospheric Research (NCAR) and has been widely used both in research communities and operational centers (Barker et al., 2012; Huang et al., 2009; Wang et al., 2013b). A brief description of WRFDA will be presented in the next section. In the blending scheme, a low-pass filter is required to obtain large-scale information from host and regional models. In this paper, a low-pass Raymond sixth-order tangent implicit filter (Raymond and Garder, 1991) is employed to obtain large-scale information in $x^{\mathrm{h}}$ and $x^{\mathrm{r}}$. The amplitude response function of the Raymond sixth-order tangent implicit filter to length scale $l$ is expressed as

$$
\begin{aligned}
& \alpha(l)=\left[1+\varepsilon \tan ^{6}\left(\frac{\pi \delta x}{l}\right)\right]^{-1}, \\
& \varepsilon=\tan ^{-6}\left(\frac{\pi \delta x}{l_{\mathrm{c}}}\right),
\end{aligned}
$$

where $\varepsilon$ is the filter parameter, which depends on grid spacing $\delta x$ and cut-off length scale $l_{\mathrm{c}}$. From Eqs. (9) and (10), it is seen that when the wavelength equals the cut-off length scale $\left(l=l_{\mathrm{c}}\right)$, the filter possesses a half power $(\alpha(l)$ is 0.5$)$. Figure 1 shows the amplitude responses for the Raymond tangent implicit filter as a function of wavelength, with the cut-off length scales at 1200 and $600 \mathrm{~km}$. It is seen that the filter has larger amplitude responses at longer wavelength scales and smaller amplitude responses at shorter wavelength scales, indicating that the filter can keep more information at large scale $\left(\sum_{l} \alpha(l) x^{\mathrm{h}}(l)\right)$ from a host model (e.g., GFS), and more information at small scale $\left(\sum_{l} \phi^{\mathrm{r}}(l)\right)$ from a regional model (e.g., WRF). It is also seen that the low-pass filter keeps the signals with a length scale larger than $3000 \mathrm{~km}$ when the cut-off scale is $1200 \mathrm{~km}$ (Fig. 1a). The filter keeps most of the signal whose scale is larger than $1000 \mathrm{~km}$ when the cut-off scale is $600 \mathrm{~km}$ (Fig. 1b). This indicates that the blending method will keep more large-scale information with a cut-off length scale of $600 \mathrm{~km}$ than it will with $1200 \mathrm{~km}$. The cut-off length scale decides how much information from the host model and regional model is kept in the blended fields. In general, the smaller the cut-off length scale is, the more information from the host model is used in the blending scheme.
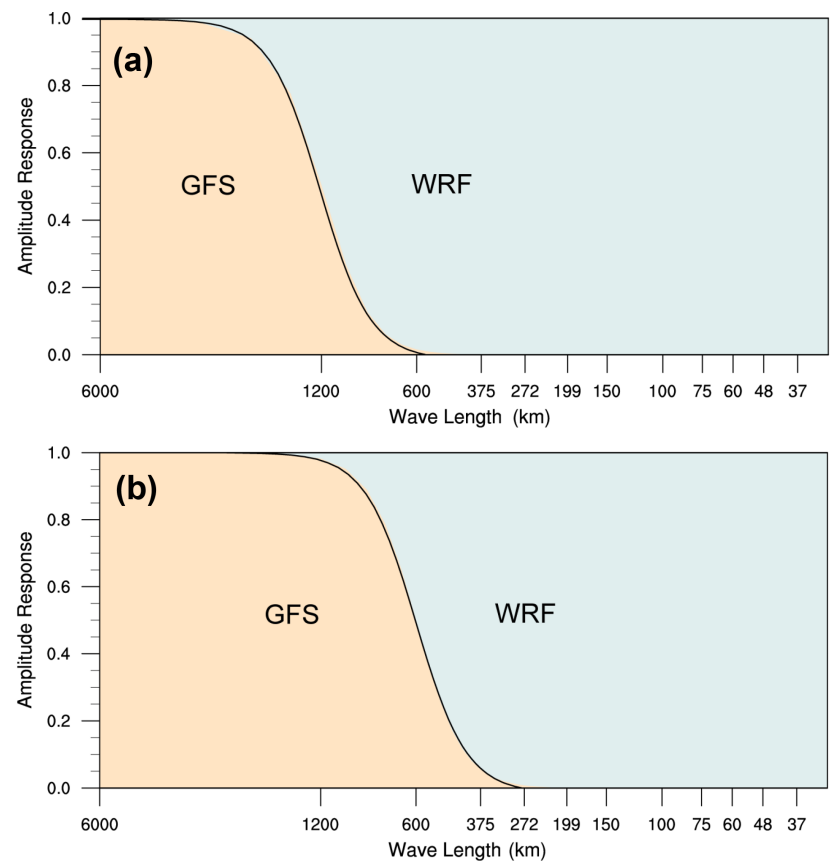

Figure 1. Amplitude responses for the Raymond filter as a function of wavelength with cut-off wavelength (a) $1200 \mathrm{~km}$, and (b) $600 \mathrm{~km}$. The GFS and WRF are demonstrated as a host model and a nested model, respectively.

In WRFDA, the background is usually provided by a shortterm WRF forecast from a previous cycle. In the background blending scheme, the short-term WRF forecast is blended with a GFS short-term forecast at the same time, and then this blended forecast is regarded as the background for WRFDA. In the analysis blending scheme, the WRFDA analysis is blended with a GFS analysis to form a new analysis which provides the initial condition for next WRF cycle. The blended variables include the WRF model prognostic variables such as perturbation geopotential height, perturbation potential temperature, $u$ and $v$ wind, water vapor mixing ratio, perturbation pressure, and perturbation dry surface pressure.

\subsection{Performance of spatial filter: an illustrative example}

Before discussing the impact of the blending scheme in real data assimilation and forecasting experiments, the performance of the Raymond spatial filter is investigated. An illustrative example of geopotential height at 06:00 UTC on 8 September 2012 is shown in this section.

The GFS $6 \mathrm{~h}$ geopotential height forecast at 06:00 UTC on 8 September 2012, with its filtered fields having cutoff length scales of 1200 and $600 \mathrm{~km}$, is shown in Fig. 2ac respectively. The WRF $6 \mathrm{~h}$ forecast and its differences from filtered fields, having cut-off length scales of 1200 and $600 \mathrm{~km}$, are shown in Fig. 2d-f respectively. Figure $2 \mathrm{~g}$ and $\mathrm{h}$ show the blended fields using Eq. (6c). The filtered fields 
(a)

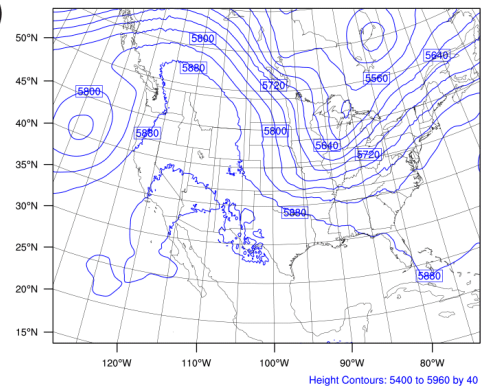

(c)

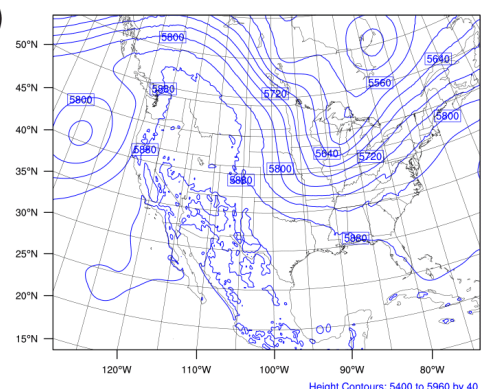

(e)

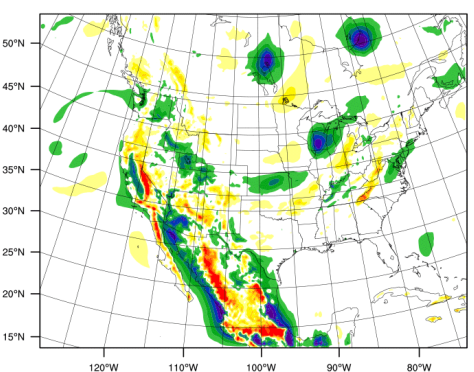

(g)

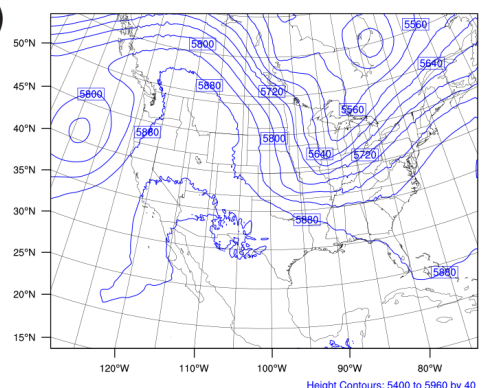

(i)

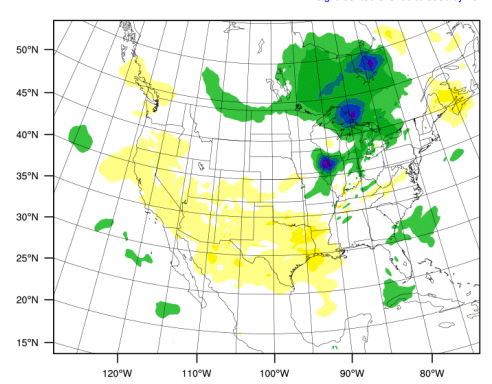

(b)

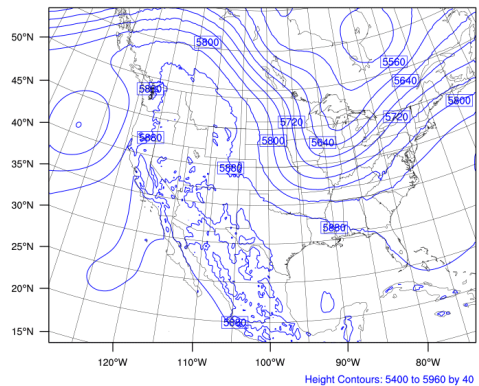

(d)

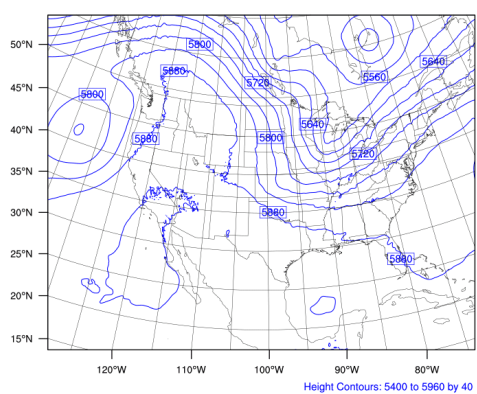

(f)

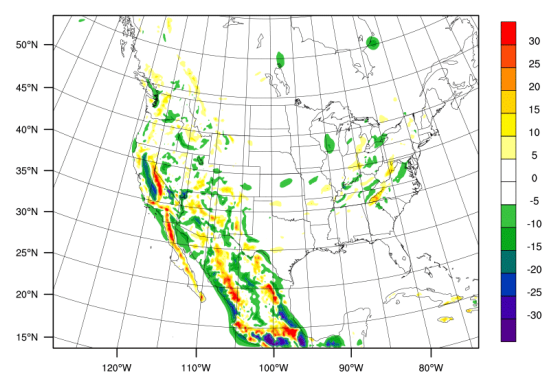

(h)

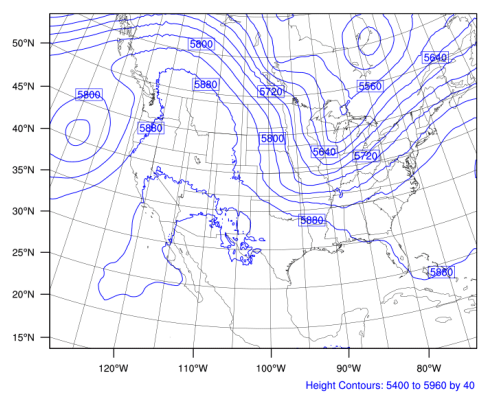

${ }_{30}(j)$

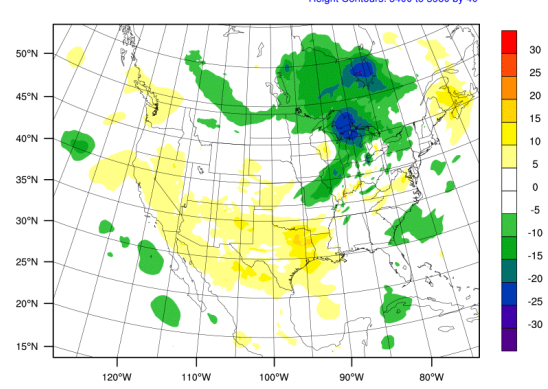

Figure 2. $500 \mathrm{hPa}$ geopotential height at 06:00 UTC on 8 September 2012. (a) GFS $6 \mathrm{~h}$ forecast, its filtered field with cut-off length scale (b) $1200 \mathrm{~km}$, (c) $600 \mathrm{~km}$; (d) WRF $6 \mathrm{~h}$ forecast, differences from its filtered fields with cut-off length scale (e) $1200 \mathrm{~km}$, (f) $600 \mathrm{~km}$; blended fields with cut-off length scale (g) $1200 \mathrm{~km}$ and (h) $600 \mathrm{~km}$; blended fields minus WRF $6 \mathrm{~h}$ forecast with cut-off length scale (i) $1200 \mathrm{~km}$ and (j) $600 \mathrm{~km}$. 
become smoother when the cut-off length scale becomes larger (Fig. 2b and c). Those filtered fields represent the large-scale information $\left(\sum_{l} \alpha(l) x^{\mathrm{h}}(l)\right)$ that is kept in blended fields (Fig. 2g and h) using Eq. (6c).

The differences showed in Fig. 2e and f represent the small-scale information $\left(\sum_{l} \phi^{\mathrm{r}}(l)\right)$ that is kept in blended fields (Fig. 2g and h). According to the response function (Fig. 1) and residuals (Fig. 2e and f), the blended fields with the cut-off length scale of $1200 \mathrm{~km}$ (Fig. $2 \mathrm{~g}$ ) will keep more information from WRF forecast compared to that with $600 \mathrm{~km}$ (Fig. 2h).

We also investigated the large-scale adjustment represented by the second term in Eq. (4). It is obvious that there is a large-scale adjustment of geopotential height with onewave pattern in the south-north direction for this case (Fig. 2i and $\mathrm{j}$ ). The adjustment of the fields becomes smoother when the cut-off length scale becomes larger.

\section{Experiments}

\subsection{The WRF model and WRFDA system}

The WRF model with version 3.4.1 (Skamarock et al., 2008) is used in this study. The model physics options in this paper include the RRTMG longwave and shortwave radiation schemes, MYJ planetary boundary layer scheme, MoninObukhov surface layer scheme, unified Noah land-surface model, Morrison two-moment microphysics, and Tiedtke cumulus parameterization. Descriptions of the above physical process schemes can be found in the WRF technical report by Skamarock et al. (2008). The WRFDA's threedimensional variational data assimilation component (WRF 3D-Var; Barker et al., 2004, 2012) is used in this study. The control variables with option 5 (CV5) in the WRFDA are stream function, unbalanced part of velocity potential, unbalanced part of temperature, unbalanced surface pressure, and pseudo relative humidity.

\subsection{Experiment design}

Before performing the blending experiments, response functions to various cut-off length scales are examined to aid in selecting cut-off length scales. In addition to response functions, the size of model domain, and experiences and knowledge on data assimilation systems may help to select the cutoff length scales as well. In this paper, the response functions using cut-off length scales of 1200 and $600 \mathrm{~km}$ are used and shown in Fig. 1. The two cut-off length scales of 600 and $1200 \mathrm{~km}$, which can keep the large-scale components in GFS with wavelengths above 1000 and $3000 \mathrm{~km}$ respectively, are selected in this paper, since the wavelength above $3000 \mathrm{~km}$ might not be well presented in the current model domain region of about $6300 \mathrm{~km} \times 4800 \mathrm{~km}$.
A single model domain (Fig. 2a) that covers the continental United States (CONUS), with $425 \times 325 \times 40$ grids, is used in all the data assimilation and forecast experiments. The grid spacing is $15 \mathrm{~km}$. The background error statistics are generated from the difference between pairs of $24 \mathrm{~h}$ and $12 \mathrm{~h}$ forecasts valid at the same time in August 2012, and $24 \mathrm{~h}$ forecasts initiated from GFS analyses are made twice a day (00:00 and 12:00 UTC) to generate a forecast difference ensemble to model background error covariance.

A set of experiments (Table 1) is conducted to assess the impact of the blending scheme and data assimilation on regional forecasting. For each experiment, one 2-weeklong period run from 1 to 14 September 2012 is conducted. The control experiment is the full cycle experiment (FullCycle), which assimilates operational conventional observations from the Global Telecommunication System (GTS) data set at NCEP.

Two background blending experiments with cut-off length scales of 600 and $1200 \mathrm{~km}$ are carried out. Hereafter, the two experiments are named as BLD_DA_600 and BLD_DA_1200 respectively. The blending is performed before data assimilation in the two blending experiments. In order to show the added values of data assimilation, another two forecasting experiments, which are initiated from the blended background fields of the above two blending experiments BLD_DA_600 and BLD_DA_1200, are conducted. The two forecasting experiments are named BLD_FC_600 and BLD_FC_1200 respectively.

Another two analysis blending experiments with cut-off length scales of 600 and $1200 \mathrm{~km}$ respectively are also carried out. Hereafter, the two experiments are named as BLD_ANA_600 and BLD_ANA_1200 respectively. In the analysis blending scheme, the WRFDA analysis is blended with the GFS analysis to form a new analysis which provides the initial condition for this WRF cycle. The last experiment (named GFS) initialized the forecast from the GFS analysis without assimilation or blending.

All the experiments were run in a full $6 \mathrm{~h}$ cycle mode. The data assimilation cycle began at 06:00 UTC on 1 September and ended at 12:00 UTC on 14 September 2012. The background in the first cycle is the WRF $6 \mathrm{~h}$ forecasts that were initiated from the GFS analysis at 00:00 UTC on 1 September 2012. The backgrounds in following cycles are provided by $6 \mathrm{~h}$ WRF forecasts from the previous cycles. For each experiment, $36 \mathrm{~h}$ forecasts are made every $12 \mathrm{~h}$ (00:00 and 12:00 UTC). The skills of bias and root mean square error of $u, v$ wind, temperature, and humidity were calculated against ECMWF reanalysis. 
Table 1. Experiment descriptions.

\begin{tabular}{lll}
\hline EXP Name & Cut-off length scale & Initial conditions \\
\hline FullCycle & No & WRFDA analysis \\
BLD_DA_600 & 600 & WRFDA analysis \\
BLD_DA_1200 & 1200 & WRFDA analysis \\
BLD_FC_600 & 600 & Blended background from BLD_DA_600 \\
BLD_FC_1200 & 1200 & Blended background from BLD_DA_1200 \\
BLD_ANA_600 & 600 & WRFDA analysis blended with GFS analysis \\
BLD_ANA_1200 & 1200 & WRFDA analysis blended with GFS analysis \\
GFS & No & GFS analysis \\
\hline
\end{tabular}

\section{Results}

\subsection{Forecast error in the full cycle experiment}

Previous studies found that the LAM analyses and forecasts suffer a general deficiency in effectively representing largescale features. The features of the $6 \mathrm{~h}$ forecast error in the control experiment FullCycle are first investigated to assess whether a WRFDA system running in full cycle mode produces large-scale forecasting errors. Then WRFDA with the blending scheme is examined to show the benefits of the blending scheme.

Figure 3a shows the averaged geopotential height difference between WRF $6 \mathrm{~h}$ forecast and the ECMWF (European Center for Medium range Weather Forecasting) reanalysis ${ }^{1}$ (Dee et al., 2011) from 18:00 UTC on 1 September 2012 to 06:00 UTC on 14 September 2012. It is well known that the ECMWF reanalysis has high accuracy and thus is used as a reference. It is clearly seen that there is a systematic larger-scale difference with wave number 1 structure in the north-south direction. The averaged geopotential height differences between BLD_DA_1200 and the ECMWF reanalysis, and between BLD_ANA_1200 and the ECMWF reanalysis, are shown in Fig. $3 b$ and c. They show the performance of the background and analysis blending schemes. Compared to the FullCycle experiment (Fig. 3a), the analysis blending scheme (Fig. 3c) is more efficient than the background blending scheme (Fig. 3b) in reducing the large-scale error.

\subsection{Verifications}

\subsubsection{Accuracy of analyses and forecasts}

A total of 27 analyses and WRF forecasts up to $36 \mathrm{~h}$ are verified against the ECMWF reanalysis from 12:00 UTC on 1 September 2012 to 12:00 UTC on 14 September 2012. It is well known that the ECMWF reanalysis has high accuracy

\footnotetext{
${ }^{1}$ European Centre for Medium-Range Weather Forecasts. 2009, updated monthly. ERA-Interim Project. Research Data Archive at the National Center for Atmospheric Research, Computational and Information Systems Laboratory. http://rda.ucar.edu/datasets/ ds627.0.
}
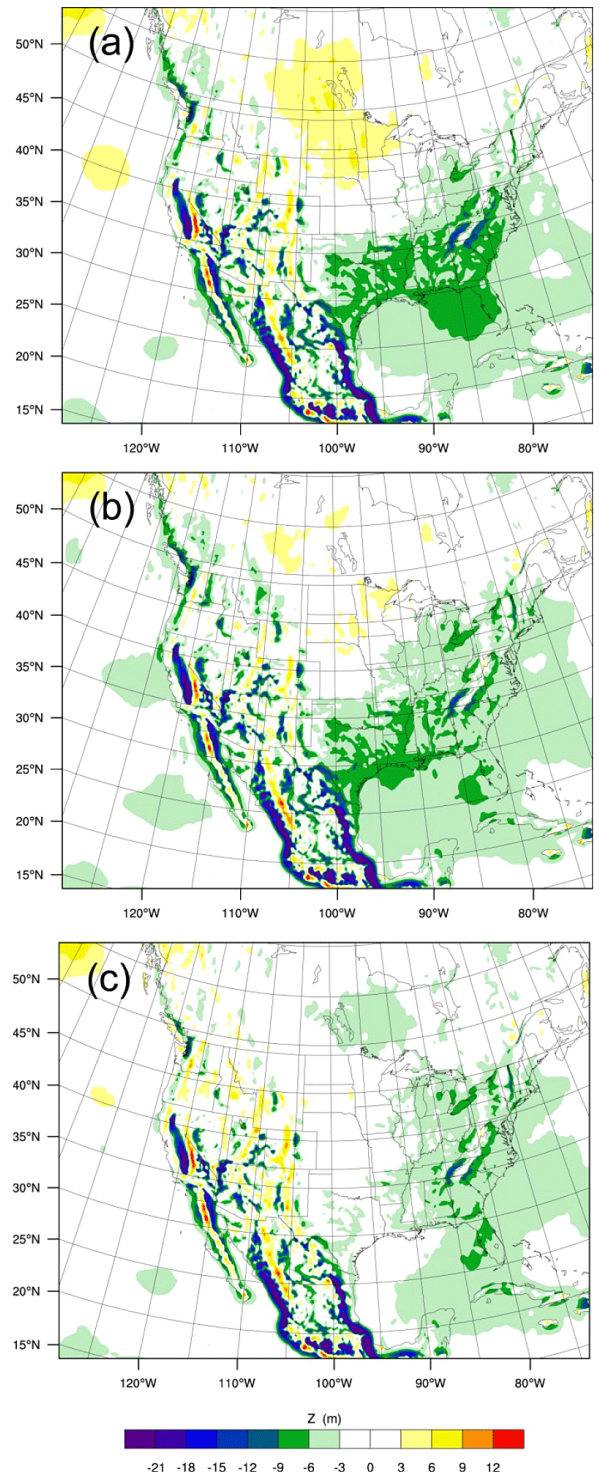

Figure 3. Averaged geopotential height differences at $500 \mathrm{hPa}$ between (a) WRF $6 \mathrm{~h}$ forecast and ECMWF reanalysis, (b) BLD_DA_1200 $6 \mathrm{~h}$ forecast and ECMWF reanalysis, (c) BLD_ANA_1200 $6 \mathrm{~h}$ forecast and ECMWF reanalysis. 

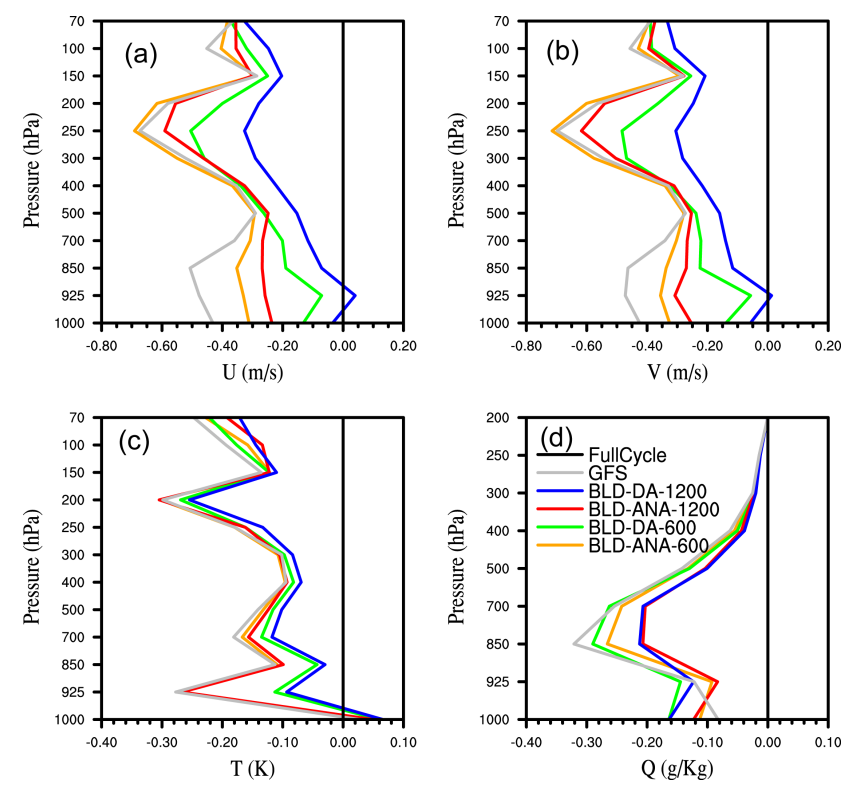

Figure 4. RMSD reduction compared to FullCycle at analysis time. (a) $u$, (b) $v$, (c) $T$, and (d) $q$.

and thus is used as a reference. Root-mean-square difference (RMSD) for $u, v$, temperature $(T)$, and specific humidity $(q)$ in each experiment was calculated, and then the relative RMSD reductions in the GFS experiments and four blending experiments were obtained by subtracting the RMSD in the FullCycle experiment. A negative value of the RMSD reduction means the analysis/forecast is more accurate than those in the FullCycle experiment. Vertical profiles of the RMSD reductions in the GFS experiments and the four blending experiments at analysis time and $24 \mathrm{~h}$ forecast time are shown in Figs. 4 and 5 respectively.

Overall, analysis errors for all the variables in the four blending experiments are reduced compared to the control FullCycle experiment. The analysis errors for wind are reduced at almost all the levels, with the maximum error reductions around 250 and $850 \mathrm{hPa}$. The temperature analysis accuracy is improved over all the levels except for the surface level. For humidity, the analysis accuracy is significantly improved at about $850 \mathrm{hPa}$.

It is seen that the GFS analysis is more accurate than the four blending experiments. In addition, the analysis blending produces a more accurate analysis than the background blending. As for the $24 \mathrm{~h}$ forecasts (Fig. 5), the blending experiments give consistent improvement compared to the FullCycle experiment for all variables. The forecast errors for wind and temperature in the analysis blending and GFS experiments are smaller than the background blending experiment.

The added values of data assimilation are assessed and shown in Figs. 6 and 7. From Fig. 6, it is seen that the data assimilation shows slightly negative impacts on wind analysis,
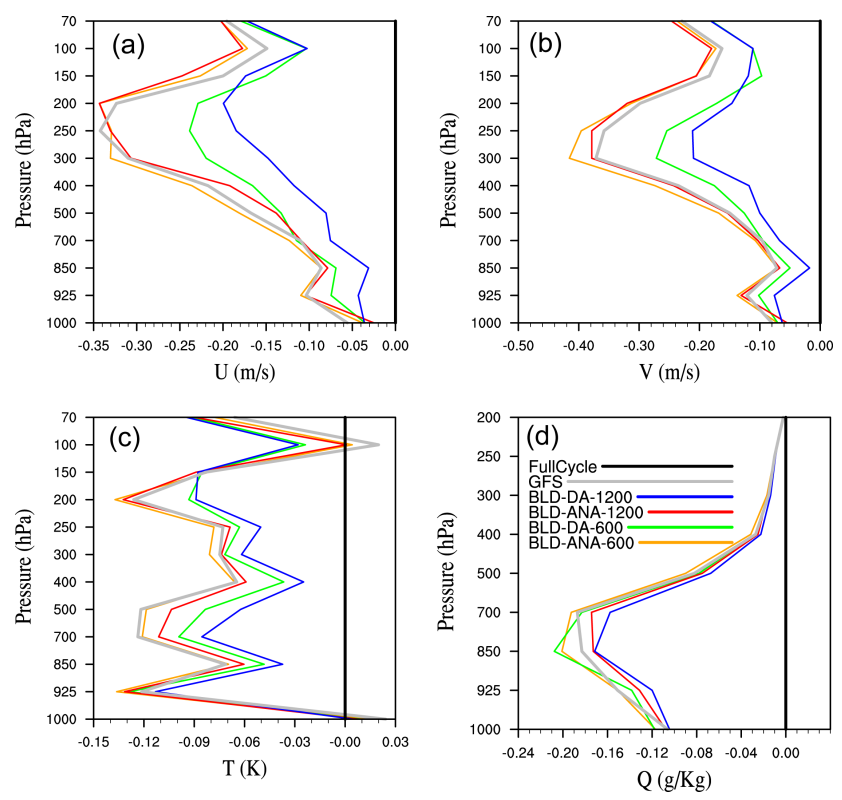

Figure 5. Same to Fig. 4 but for $24 \mathrm{~h}$ forecast RMSD reduction compared to FullCycle. (a) $u$, (b) $v$, (c) $T$, and (d) $q$.

but significant positive impacts on temperature analysis over $700 \mathrm{hPa}$ and humidity analysis. Wang et al. (2014) found that $u$ and $v$ wind variances are underestimated when the default control variable option (CV5) in WRFDA is used. This underestimation reduces weights of wind observations, which may partially explain that the wind analysis is not improved in the data assimilation experiment. As for the $24 \mathrm{~h}$ forecasts (Fig. 7), the forecast errors in the data assimilation experiments (BLD-DA-1200 and BLD-DA-600) are smaller than those in the experiment BLD-FC-1200 and BLD-FC-600.

\subsubsection{Precipitation forecast skill}

To evaluate the precipitation forecast skill, equitable threat scores (ETSs) and bias scores for the $1 \mathrm{~h}$ accumulated precipitation forecast, in the threshold $1 \mathrm{~mm}$, in the first $6 \mathrm{~h}$, are plotted in Fig. 8. The stage-IV $4 \mathrm{~km}$ hourly precipitation analysis is used as "observations" in the verification. The stage-IV precipitation product is the regional multisensor precipitation analyses at NCEP (Lin and Mitchell, 2005). In general, the ETSs in the four blending experiments are higher than the FullCycle experiment. It is noted that the analysis blending experiments yield the best results. They are even better than the GFS experiment. It is clear that the GFS experiment needs about $2 \mathrm{~h}$ to spin up. This will be discussed in the next section. As for the bias (Fig. 8b), the precipitation frequency in the FullCycle experiment is close to the stageIV precipitation observations. The biases in the four blending experiments are lower than that in FullCycle indicating that the higher ETS in the blending experiments is not caused by the overprediction of precipitation, but due to improved precipitation forecast in rain region coverage. 

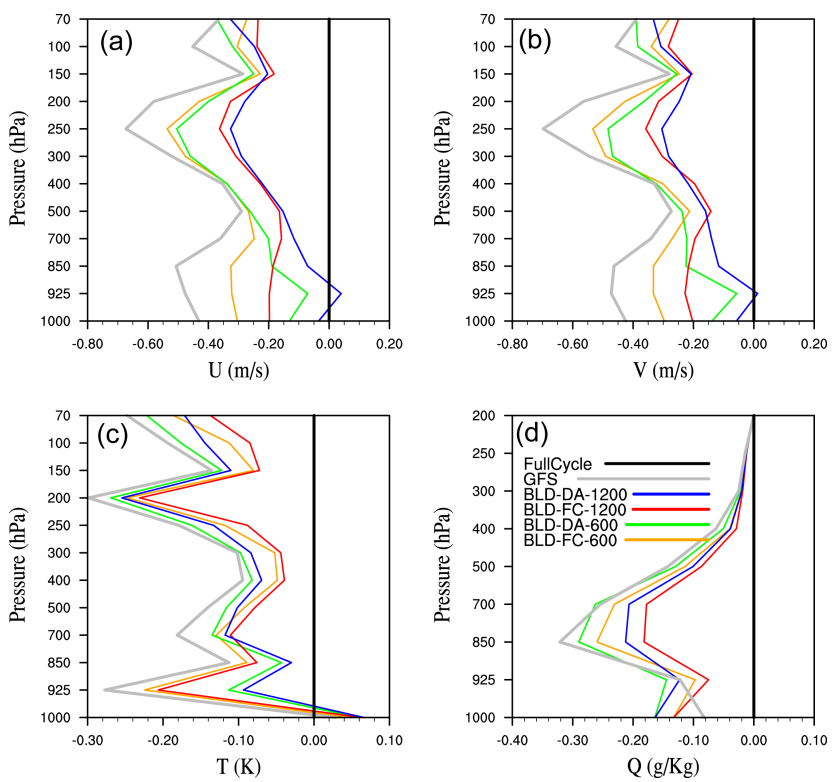

Figure 6. RMSD reduction compared to FullCycle at analysis time. (a) $u$, (b) $v$, (c) $T$, and (d) $q$.
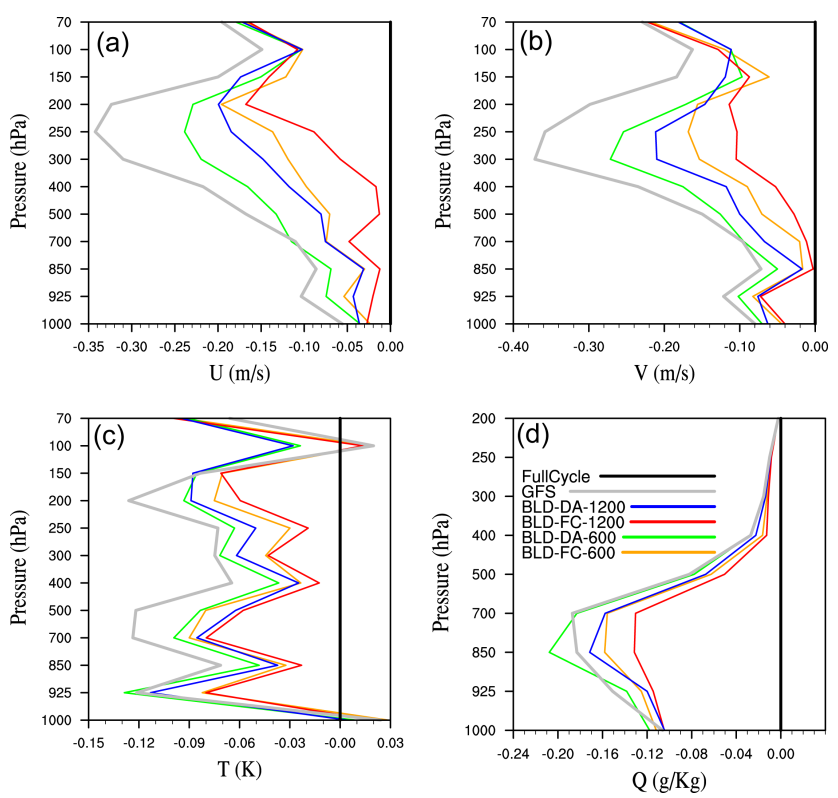

Figure 7. Same to Fig. 6 but for $24 \mathrm{~h}$ RMSD reduction compared to the experiment FullCycle. (a) $u$, (b) $v$, (c) $T$, and (d) $q$.

\subsection{Spin-up issues}

The cycling data assimilation and forecast experiments using the blending scheme have the merits of using large-scale information from GFS, as well as small-scale features that have been built up in previous WRF forecast cycles. It is noted that large-scale information introduced into the WRFDA analyses may need time to spin up in a regional model. However, small-scale features carried over from previous cycles may
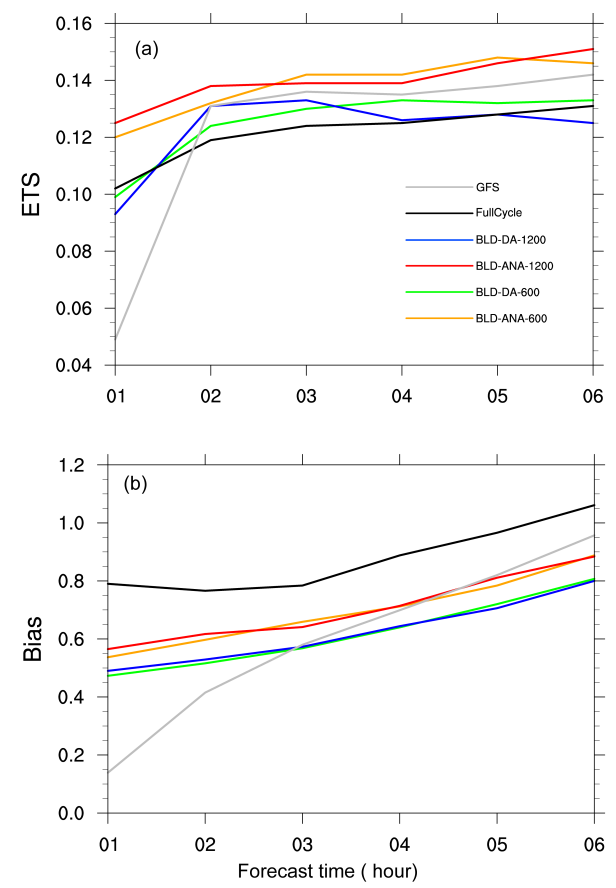

Figure 8. Averaged hourly accumulated precipitation forecast skill for the threshold $1 \mathrm{~mm}$ (a) ETS and (b) bias.

help to partially mitigate this issue. In this paper, the mean absolute surface pressure tendency is used to reflect the overall balance of the model states (Lynch and Huang, 1992). Precipitation tendency is also investigated to show the spinup feature of moisture fields.

Figure 9 shows the evolution of domain- and timeaveraged total absolute surface pressure tendency, and precipitation tendency at each time step for the six experiments. It is obvious that forecasts initiated from GFS analyses show significant imbalance in the first few hours of the forecast, especially in the beginning of the forecast. Both the total absolute surface pressure tendency and precipitation tendency in the GFS experiment gradually become close to those in the FullCycle experiment after $3 \mathrm{~h}$. The forecasts from the blending experiments do introduce noise, but the total absolute surface pressure tendency and precipitation tendency are much closer to those in the FullCycle experiment.

The averaged $1 \mathrm{~h}$ accumulated precipitation in the first forecast hour is shown in Fig. 10. The GFS produces the slightest amount of precipitation among all the experiments. This result is consistent with Fig. 9. The patterns of accumulated precipitation from the blended experiments are very similar to the FullCycle forecast. Compared to the GFS experiment, the experiments using the blending scheme are less bothered by spin-up issues. 

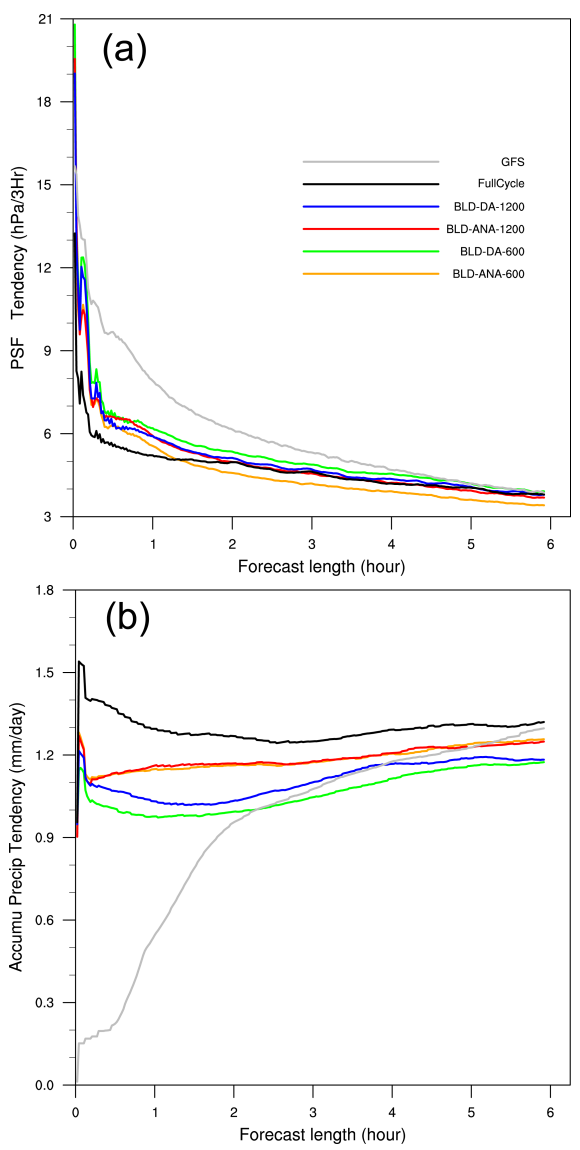

Figure 9. The evolution of domain- and time-averaged (a) total absolute surface pressure tendency, and (b) precipitation tendency.

\section{Summary}

Regional weather forecasts suffer a general deficiency in effectively representing of large-scale features, such as those in global analyses and forecasts due to limitation of the domain size and limited observations used in regional data assimilation and forecasting systems. In this paper, a scaledependent blending scheme using the low-pass Raymond sixth-order tangent implicit spatial filter was implemented in the WRFDA system to improve large-scale weather features in the WRFDA analyses. The low-pass Raymond sixthorder tangent implicit filter was used to split fields from the host model and regional model into components at different scales, which are then blended to form new fields that include more large-scale information from the host model and more small-scale information from the regional model.

Full cycle data assimilation and forecasting experiments for one 2-week-long period in September 2012 were conducted to evaluate the impact of the blending method on regional forecasts. It is found that there are obvious largescale forecast errors in the regional WRFDA system running in full cycle mode. The developed scale-dependent blending scheme is efficient in introducing large-scale information in
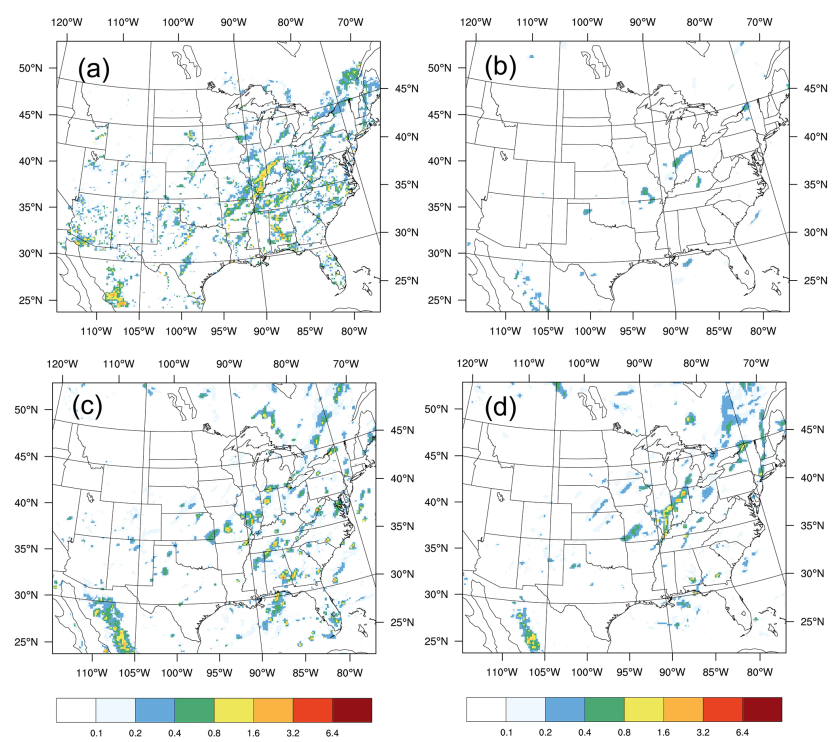

Figure 10. Averaged accumulated precipitation (unit: $\mathrm{mm}$ ) in the first forecast hour. (a) Stage IV observation, experiment (b) GFS, (c) FullCycle, and (d) BLD_ANA_600.

the host GFS model to the regional WRF model. Results indicate that the blending method reduces the WRFDA analysis error that results in a reduction of WRF forecast errors for wind, temperature, and humidity up to $24 \mathrm{~h}$. The blending experiments yield the better precipitation forecast skills compared to the full cycle experiment.

In the blending scheme, the accuracy of analysis at the large scale depends on the quality of host model products, whereas the analysis of small-scale features of atmospheric weather systems is influenced by the WRFDA system and model dynamics implicated in cycled background. More observations (e.g., from a local dense observing network or radars) are expected to increase analysis accuracy of the small-scale atmospheric systems, which is beneficial to precipitation forecast. In addition, the improvements in the large-scale atmospheric systems are crucial for tropical cyclone forecasts. The developed blending scheme has been in operation for typhoon forecasting at Central Weather Bureau (CWB). The scheme greatly increased the operational typhoon track forecast during the 2012 season, and a detailed investigation will be reported in a future paper.

Acknowledgements. The authors thank X. Yang at DMI for constructive discussions. The authors also thank J. Osborn at NOAA for providing editorial support for this manuscript. NCAR is sponsored by the National Science Foundation. Any opinions, findings, and conclusions or recommendations expressed in this publication are those of the authors and do not necessarily reflect the views of the National Science Foundation.

Edited by: J. Annan 


\section{References}

Barker, D. M., Huang, W., Guo, Y.-R., Bourgeois, A. J., and Xiao, Q. N.: A three-dimensional variational data assimilation system for MM5: Implementation and initial results, Mon. Weather Rev., 132, 897-914, 2004.

Barker, D., Huang, X.-Y., Liu, Z., Auligné, T., Zhang, X., Rugg, S., Ajjaji, R., Bourgeois, A., Bray, J., Chen, Y., Demirtas, M., Guo, Y.-R., Henderson, T., Huang, W., Lin, H.-C., Michalakes, J., Rizvi, S., and Zhang, X.: The Weather Research and Forecasting (WRF) Model's Community Variational/Ensemble Data Assimilation System: WRFDA, B. Am. Meteorol. Soc., 93, 831843, 2012.

Brozkova, R., Klaric, D., Ivatek-Sahdan, S., Geleyn, J.-F., Casse, V., Siroka, M., Radnoti, D., Janousek, M., Stadlbacher, K., and Seidl, H.: DFI Blending, an alternative tool for preparation of the initial conditions for LAM, PWRP Report Series No. 31, WMOTD, No. 1064, 2001.

Dahlgren, P. and Gustafsson, N.: Assimilating host model information into a limited area model, Tellus A, 2012, 15836, doi:10.3402/tellusa.v64i0.15836, 2012.

Dee, D. P., Uppala, S. M., Simmons, A. J., et al.: The ERA-Interim reanalysis: configuration and performance of the data assimilation system, Q. J. Roy. Meteorol. Soc., 137, 553-597, 2011.

Eerola, K.: Twenty-One Years of Verification from the HIRLAM NWP System, Weather Forecast., 28, 270-285, doi:10.1175/WAF-D-12-00068.1, 2013.

Guidard, V. and Fischer, C.: Introducing the coupling information in a limited-area variational assimilation, Q. J. Roy. Meteorol. Soc., 134, 723-736, 2008.

Hsiao, L.-F., Chen, D.-S., Kuo, Y.-H., Guo, Y.-R., Yeh, T.-C., Hong, J.-S., Fong, C.-T., and Lee, C.-S.: Application of WRF 3DVAR to Operational Typhoon Prediction in Taiwan: Impact of Outer Loop and Partial Cycling Approaches, Weather Forecast., 27, 1249-1263, doi:10.1175/WAF-D-11-00131.1, 2012.

Huang, X.-Y., Xiao, Q., Barker, D. M., Zhang, X., Michalakes, J., Huang, W., Henderson, T., Bray, J., Chen, Y., Ma, Z., Dudhia, J., Guo, Y., Zhang, X., Won, D.-J., Lin, H.-C., and Kuo, Y.-H.: FourDimensional Variational Data Assimilation for WRF: Formulation and Preliminary Results, Mon. Weather Rev., 137, 299-314, 2009.

Lin, Y. and Mitchell, K. E.: The NCEP stage II/IV hourly precipitation analysis: Development and applications. Preprints, 19th Conf. on Hydrology, San Diego, CA, Amer. Meteor. Soc., P1.2, 2005.
Liu, B. and Xie, L.: A Scale-Selective Data Assimilation Approach to Improving Tropical Cyclone Track and Intensity Forecasts in a Limited-Area Model: A Case Study of Hurricane Felix (2007), Weather Forecast., 27, 124-140, 2012.

Lynch, P. and Huang, X.-Y.: Initialization of the HIRLAM Model Using a Digital Filter, Mon. Weather Rev., 120, 1019-1034, 1992.

Raymond, W. H.: High-Order Low-Pass Implicit Tangent Filters for Use in Finite Area Calculations, Mon. Weather Rev., 116, 21322141, 1988.

Raymond, W. H. and Garder, A.: A Review of Recursive and Implicit Filters, Mon. Weather Rev., 119, 477-495, 1991.

Skamarock, W. C., Klemp, J. B., Dudhia, J., Gill, D. O., Barker, D. M., Duda, M. G., Huang, X.-Y., Wang, W., and Powers, J. G.: A description of the Advanced Research WRF version 3, NCAR Tech. Rep. TN-475 + STR, 113 pp., 2008.

Sun, J., Trier, S. B., Xiao, Q., Weisman, M. L., Wang, H., Ying, Z., Xu, M., and Zhang, Y.: Sensitivity of 0-12-h Warm-Season Precipitation Forecasts over the Central United States to Model Initialization, Weather Forecast., 27, 832-855, 2012.

Termonia, P., Deckmyn, A., and Hamdi, R.: Study of the Lateral Boundary Condition Temporal Resolution Problem and a Proposed Solution by Means of Boundary Error Restarts, Mon. Weather Rev., 137, 3551-3566, 2009.

Tudor, M. and Termonia, P.: Alternative Formulations for Incorporating Lateral Boundary Data into Limited-Area Models, Mon. Weather Rev., 138, 2867-2882, 2010.

Wang, H., Sun, J., Fan, S., and Huang, X.-Y.: Indirect Assimilation of Radar Reflectivity with WRF 3D-Var and Its Impact on Prediction of Four Summertime Convective Events, J. Appl. Meteorol. Clim., 52, 889-902, 2013a.

Wang, H., Sun, J., Zhang, X., Huang, X.-Y., and Auligné, T.: Radar Data Assimilation with WRF 4D-Var: Part I. System Development and Preliminary Testing, Mon. Weather Rev., 141, 22242244, 2013b.

Wang, H., Huang, X.-Y., Sun, J., Xu, D., Zhang, M., Fan, S., and Zhong, J.: Inhomogeneous Background Error Modeling for WRF-Var using the NMC method, J. Appl. Meteorol. Clim., online first, doi:10.1175/JAMC-D-13-0281.1, 2014.

Yang, X.: Analysis blending using a spatial filter in grid-point model coupling, HIRLAM Newsletter, 48, 49-55, 2005 a.

Yang, X.: Background blending using a spatial filter, HIRLAM Newsletter, 49, 3-11, 2005b. 